\title{
Downregulation of SS18-SSX1 expression in synovial sarcoma by small interfering RNA enhances the focal adhesion pathway and inhibits anchorage-independent growth in vitro and tumor growth in vivo
}

\author{
SATOSHI TAKENAKA ${ }^{1,3}$, NORIFUMI NAKA ${ }^{1,2}$, NOBUHITO ARAKI ${ }^{2}$, NOBUYUKI HASHIMOTO $^{3}$, \\ TAKAFUMI UEDA ${ }^{4}$, KIYOKO YOSHIOKA $^{1}$, HIDEKI YOSHIKAWA ${ }^{3}$ and KAZUYUKI ITOH ${ }^{1}$
}

\begin{abstract}
${ }^{1}$ Department of Biology and ${ }^{2}$ Musculoskeletal Oncology Service, Osaka Medical Center for Cancer and Cardiovascular Diseases, 1-3-2 Nakamichi, Higashinari-ku, Osaka 537-8511; ${ }^{3}$ Department of Orthopaedic Surgery, Osaka University Graduate School of Medicine, 2-2 Yamadaoka, Suita, Osaka 565-0871; ${ }^{4}$ Department of Orthopaedic Surgery, Osaka National Hospital, Kinki-Block Comprehensive Cancer Center, 2-1-14 Hoenzaka, Chuo-ku, Osaka 540-0006, Japan
\end{abstract}

Received November 17, 2009; Accepted January 11, 2010

DOI: 10.3892/ijo_00000559

\begin{abstract}
Synovial sarcoma (SS) is an aggressive soft-tissue malignancy characterized by a unique $\mathrm{t}(\mathrm{X} ; 18)$ translocation resulting in expression of SS18-SSX fusion protein. In order to investigate the biological function of this fusion protein and to develop a novel therapeutic option, we examined downregulation of SS18-SSX1 expression by small interfering RNA targeting SS18-SSX1 in three human SS cell lines. Microarray analysis comparing SS18-SSX1-silenced cells with control cells in three SS cell lines showed that SS18SSX1 mainly affected the focal adhesion pathway. In accord with the array data, silencing of SS18-SSX1 enhances adhesion to the extracellular matrix through the induction of expression of myosin light-chain kinase. Furthermore, the silencing of SS18-SSX1 inhibits anchorage-independent growth in vitro and systemic delivery of siRNA against SS18-SSX1 using a nanoparticle system inhibited tumor growth in a nude mouse xenograft model. Our results demonstrate that siRNA targeting of SS18-SSX1 has therapeutic potential for the treatment of SS.
\end{abstract}

\section{Introduction}

Synovial sarcoma (SS) accounts for 7-10\% of all soft-tissue malignancies, frequently affecting adolescents and young adults. SS is characterized by a unique genetic event, the $\mathrm{t}(\mathrm{X} ; 18)$ translocation-mediated fusion of the SS18 gene on chromosome $18 \mathrm{q} 11$ to either $S S X 1, S S X 2$, or, very rarely, the SSX4 gene located on chromosome Xp11, resulting in fusion protein product $S S 18-S S X(1-4)$.

Correspondence to: Dr Kazuyuki Itoh, Department of Biology, Osaka Medical Center for Cancer and Cardiovascular Diseases, 1-3-2 Nakamichi, Higashinari-ku, Osaka 537-8511, Japan E-mail: itou-ka@mc.pref.osaka.jp

Key words: synovial sarcoma, SS18-SSX, morphology
We previously reported the 5-year overall survival of SS patients without metastasis at first presentation to be $81.1 \%$, but SS patients with metastasis at first presentation never survive for longer than 5 years, despite high-dose chemotherapy (5). One of the factors contributing to this outcome is the multidrug resistance of metastatic tumor that develops by the time patients are treated. Thus, new therapeutic options for metastatic patients are strongly required. Tumor-specific chromosomal translocations are associated with a number of malignancies, including leukemias, sarcomas, and carcinomas. The protein products of these fusion genes provide good targets for antitumor therapies. For instance, imatinib or alltrans retinoic acid improved the prognosis of chronic myeloid leukemia or acute promyelocytic leukemia, respectively, because these small molecules specifically inhibit the function of $B C R-A B L$ or $A P L-R A R \alpha$ fusion protein (6-8). Therefore, investigation of the biological function of SS18-SSX fusion gene and inhibition of its function might lead to new therapies.

The 5 ' translocation partner SS18 is evolutionarily conserved; it is widely expressed during development and in adult tissues (9). SS18-null mice do not develop beyond E9.5 and show profound defects in vascularization, cell migration, neural tube closure, and fusion within the embryonic-maternal membranes (10). It is a putative transcriptional coactivator and is thought to act by binding to the BRM and BRG1 components of SWI/SNF chromatin remodelers $(11,12)$. The $3^{\prime}$ translocation partner SSX is a family of closely related genes on the $\mathrm{X}$ chromosome that has been reported to act as transcriptional corepressors via interaction with the RING1 and Bmi-1 components of the polycomb chromatin remodeling repressor complex and with condensed chromatin and core histones (13-15). SSX expression in adults is restricted to the testes, although it is occasionally found in certain tumors including sarcoma $(2,3,16,17)$. Because of its expression pattern, $S S X$ appears to be an ideal target for cancer vaccines (18-20). The $\mathrm{t}(\mathrm{X} ; 18)$-generated SS18-SSX fusion protein 
retains the activation domain of SS18 along the repressor domain of $S S X$, lacks a DNA-binding domain, and probably acts via interaction with chromatin remodelers $(21,22)$.

One of the difficulties in analyzing SS18-SSX function has been the lack of an appropriate model system in which to study the function of this fusion gene. Because the cell of origin of SS is unknown, most studies have relied on heterologous cell types of uncertain relevance to human disease. For instance, SS18-SSX causes oncogenic transformation when introduced into rat 3 Y1 (21), but cell death when introduced into mouse MEF (23). These results suggest that there might be differences according to cell type in gene expression associated with SS18-SSX. Therefore, the cellular background is indeed critical for determining the function of SS18-SSX fusion protein in human SS. In this study, we investigated the effect of SS18-SSX silencing by siRNA using three SS cell lines, and verified that silencing of SS18-SSX could provide a novel molecular therapy.

\section{Materials and methods}

Cell lines and cell culture. The human SS cell line YaFuSS was kindly provided by Professor J. Toguchida (Kyoto University). YamatoSS was established in our laboratory from a histologically confirmed biphasic SS developed in the thigh of a 30-year-old man. AskaSS was derived in our laboratory from pulmonary metastasis from an inguinal SS with biphasic growth pattern in a 27 -year-old man. All three cell lines were maintained in Dulbecco's minimal essential medium (DMEM) containing 10\% fetal calf serum (FCS) and $1 \mathrm{mM}$ sodium pyruvate.

RNA isolation, reverse transcription, and polymerase chain reaction $(P C R)$. Total RNA was purified with TRIzol reagent (Invitrogen). Total RNA (1 $\mu \mathrm{g})$ was used for the reverse transcription reaction with the High Capacity cDNA Reverse Transcription kit (Applied Biosystems) according to the manufacturer's instructions. PCR was performed with AmpliTaq Gold (Applied Biosystems) using the following primer sets: for SS18-SSX1, forward 5'-CAACAGCAAGAT GCATACCA-3' and reverse 5'-GGTGCAGTTGTTTCC CATCG-3'; for full-length SSXs, forward 5'-GACTTCCAG GGGAATGATTT-3' and reverse 5'-CCACGTTCTGCTTCT CATCA-3', which can amplify SSX1, SSX2, SSX3, and SSX4 but not SS18-SSX1; for full-length SS18, forward 5'-GGTGG TCCAGGTCCTCAGTA-3' and reverse 5'-TTTCTGATGCT GTCCAGTGC-3'.

RNA interference. Cells were transfected with $20 \mathrm{nM}$ siRNA using Lipofectamine 2000 reagent (Invitrogen) according to the manufacturer's instructions. The siRNA sequences were as follows: siRNA-A, sense 5'-GAAAGCAGCUGGUGAU UUAUGAAGAAG-3' and antisense 5'-UCUUCAUAAAUC ACCAGCUGCUUUCAU-3'; siRNA-B, sense 5'-CCAAGA GUUCGAUGUUAGUdTdT-3' and antisense 5'-ACUAAC AUCGAACUCUUGGdCdA-3'; siRNA-control, sense 5'-CU UACGCUGAGUACUUCGAdTdT-3' and antisense 5'-UCG AAGUACUCAGCGUAAGdTdT-3'.

Plasmid construction. cDNA of human chimeric gene SS18-SSX1 was amplified from YaFuSS. SS18 was amplified from SS18-SSX1 by adding eight amino acids at its C terminus by PCR. Amplified fragments were subcloned into EcoRI and KpnI sites of the expression vector pEGFP-C1 (Clontech), designated pEGFP-SS18-SSX1 and pEGFP-SS18. Plasmid sequences were verified with an ABI PRISM 3100 genetic analyzer. Co-transfection of these vectors $(0.5 \mu \mathrm{g} / \mathrm{ml})$ and siRNAs (50 nM) was carried out with Lipofectamine 2000 reagent (Invitrogen) according to the manufacturer's instructions. Three days after transfection, fluorescence was detected using NIBA filter sets (excitation 470-490 nm, emission $515-550 \mathrm{~nm}$ ) in an inverted microscope (IX70, Olympus).

Antibodies. The anti-SS 18 antibody (Santa Cruz Biotechnology), anti-MYLK antibody (Sigma), anti-MLC antibody (Sigma), and anti-phospho-specific MLC antibody (Cell Signaling) were purchased.

Immunoblotting. Cells were lysed on ice with SDS sample buffer (125 mM Tris-HCl, pH 6.8; 2\% SDS; 10\% glycerol; bromophenol blue) with $40 \mathrm{mM}$ of dithiothreitol; the lysates were boiled at $100^{\circ} \mathrm{C}$ for $5 \mathrm{~min}$. The proteins were separated on SDS-PAGE and transferred to nitrocellulose membranes (Bio-Rad Laboratories). The membranes were blocked with $3 \%$ BSA in PBS-0.1\% Tween-20 (T-PBS) for $1 \mathrm{~h}$ at room temperature, and incubated with primary antibody diluted in T-PBS containing $1 \% \mathrm{BSA}$ at $4^{\circ} \mathrm{C}$ overnight. The membranes were washed three times with T-PBS and incubated with secondary antibody in T-PBS at room temperature for $1 \mathrm{~h}$. After washing with T-PBS, blots were developed using a mixture of nitro blue tetrazolium (Promega) and 5-bromo-4chloro-3-indolyl-phosphate (Promega) in alkaline phosphatase buffer (100 mM Tris-HCl, pH 9.0; $150 \mathrm{mM} \mathrm{NaCl} ; 1 \mathrm{mM}$ $\mathrm{MgCl}_{2}$ ). The blots were scanned using a GT9500 flat scanner (Epson).

WST-8 assay. After siRNA transfection for $24 \mathrm{~h}$, cells were trypsinized and resuspended in 10\% FCS DMEM. An equivalent number of cells $\left(1 \times 10^{5}\right.$ cells/well) in $750 \mu \mathrm{l}$ were plated onto each well of a 12 -well plate. After incubation at $37^{\circ} \mathrm{C}$ for $48 \mathrm{~h}$, medium was changed $(500 \mu \mathrm{l} / \mathrm{well})$, and 2-(2methoxy-4-nitrophenyl)-3-(4-nitrophenyl)-5-(2,4-disulfophenyl)-2H-tetrazolium monosodium salt (WST-8, Dojindo, Kumamoto, Japan) was added (50 $\mu \mathrm{l} /$ well). The plate was further incubated at $37^{\circ} \mathrm{C}$ until color development. Absorbance was read at $450 \mathrm{~nm}$ on a plate reader (Perkin Elmer).

Microarray analysis. Target cRNA probe synthesis and hybridization were performed using Agilent's Low RNA Input Linear Amplification kit (Agilent Technologies) according to the manufacturer's instructions. Briefly, each $1 \mu \mathrm{g}$ total RNA was isolated from SS cells transfected with control and siRNA-A (YamatoSS and YaFuSS) or siRNA-B (AskaSS). Doubled-stranded cDNA was generated from each $1 \mu \mathrm{g}$ total RNA and used as a template to synthesize cRNA labeled with Cyanine 3 or Cyanine 5. Amplified cRNA was fragmented and hybridized to Agilent Whole Human genome microarray (Agilent Technologies). The hybridization images were analyzed by Agilent DNA microarray scanner (Agilent Technologies) and the data were quantified using Agilent Feature Extraction software version 9.5.3.1 (Agilent Technologies). 


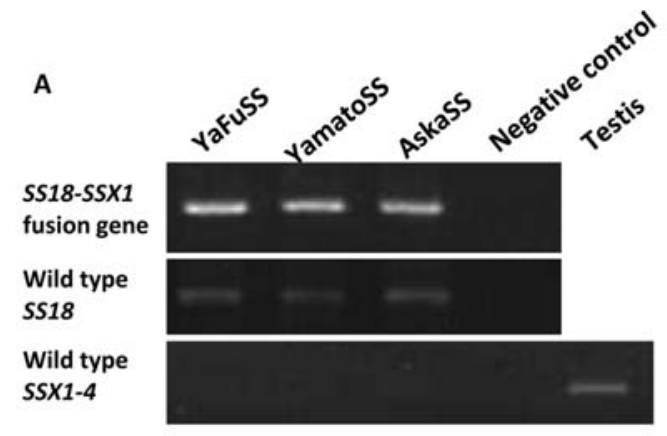

B

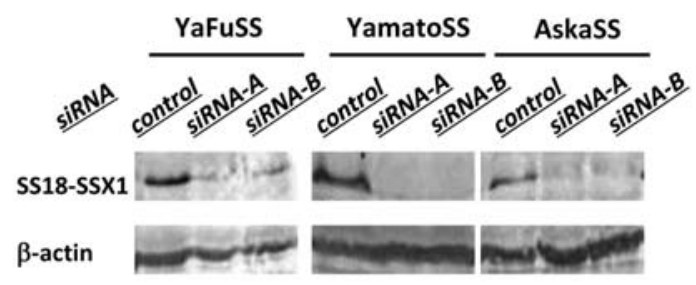

C

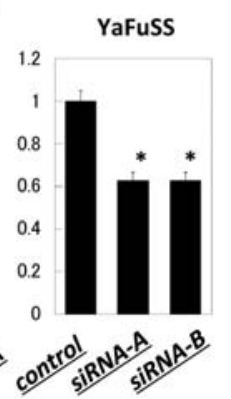

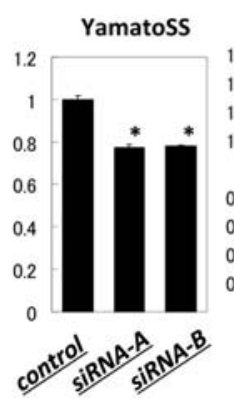

Askass

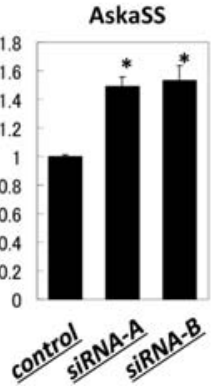

D

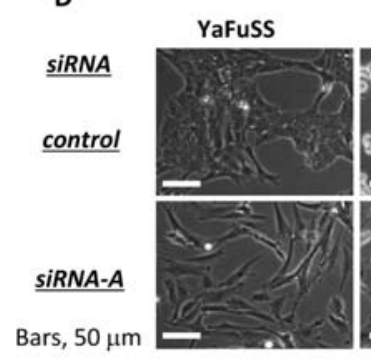

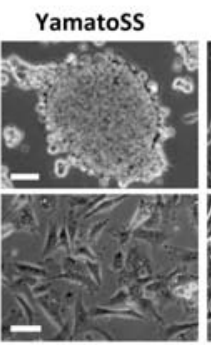

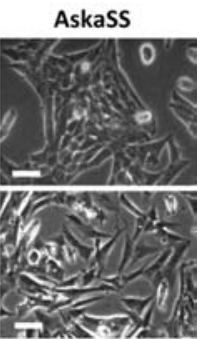

Figure 1. Silencing of SS18-SSX1 in three SS cell lines. (A) The three SS cell lines expressed both the SS18-SSX1 fusion gene and wild-type SS18 but not wild-type SSX1-4 transcripts, as revealed by RT-PCR. Testis was positive control for wild-type SSX1-4. (B) Immunoblotting analysis showed that both siRNA-A and siRNA-B effectively silenced the expression of SS18-SSX1 protein. (C) WST-8 assay for 48 h: silencing of SS18-SSX1 inhibited the growth rate of YaFuSS and YamatoSS, but enhanced it in AskaSS $(\mathrm{n}=3)$. Data are shown as mean \pm SD. ${ }^{*} \mathrm{P}<0.05$ compared with control (D) SS18-SSX1 silencing induced morphological changes in three SS cell lines. The SS18-SSX1-silenced SS cells were spread out and scattered by enhancing the cellular adhesion to the extracellular matrix. In particular, YamatoSS showed a dramatic shape change from spherical to attached on the silencing of SS18-SSX1.

All data normalization and selection of fold-changed genes were performed using GeneSpringGX 7.3.1 (Agilent Technologies). Genes were filtered with removing flag-out genes in each experiment. Intensity-dependent normalization (LOWESS) was performed. The significant gene clusters were queried with known components of the biological pathways on the Kyoto Encyclopedia of Genes and Genomes (KEGG) and GenMAPP database. The GeneSpringGX software uses the Fisher's exact test to score biochemical pathways according to the probability that as many or more genes in a pathway would be significantly altered in a given experiment as by chance alone.

Cell adhesion assay. After siRNA transfection for $72 \mathrm{~h}$, the cells $\left(2 \times 10^{5}\right.$ cells/well) were plated in 12-well culture plates and incubated at $37^{\circ} \mathrm{C}$ in a $5 \% \mathrm{CO}_{2}$ atmosphere for $1 \mathrm{~h}$ (YaFuSS and AskaSS) or $2 \mathrm{~h}$ (YamatoSS). The non-attached cells were removed by three PBS washes. The attached cells were fixed in PBS containing 3\% formaldehyde and counted under a microscopy (IX-70) using an eyepiece reticle.

Tumor sphere formation assay. SS cells $\left(6 \times 10^{4}\right.$ cells/well) transfected with siRNA were plated in 6-well ultralow attachment plates (Corning Inc., Coning, NY) in Neural Progenitor Cell medium (Lonza) containing human recombinant bFGF (Basic Fibroblast Growth Factor), EGF (Epidermal Growth
Factor), and NSF-1 (Neural Surviving Factor-1) with $0.8 \%$ methylcellulose. After culture for 7 days, the number of colonies was counted by microscopy.

Animal experiments. All animal experimental protocols were approved by the local animal ethics committee. YamatoSS cells $\left(1 \times 10^{7}\right)$ were subcutaneously implanted in nude mice. siRNA-A/WS $(100 \mu \mathrm{l})$ containing siRNA-A or saline $(100 \mu \mathrm{g})$ was intravenously injected every 3 or 4 days starting on day 3 after tumor implantation. Tumor growth was monitored by estimating its volume from caliper measurements of the length (L) and width $(\mathrm{W})$ as $\mathrm{V}=\left(\mathrm{Lx} \mathrm{W}^{2}\right) / 2$. At day 28 , the mice were sacrificed and the resected tumors were weighed.

\section{Results}

Silencing of SS18-SSX1 induced morphological changes in all three SS cell lines. In order to analyze the biological roles of SS18-SSX1 in its native cellular background, we used siRNAs to knock down the endogenous fusion protein in SS. RT-PCR showed that all three SS cell lines expressed both SS18-SSX1 fusion gene and wild-type SS18, but not wild-type $S S X 1, S S X 2, S S X 3$, and SSX4 transcripts (SSX1-4) (Fig. 1A). Thus, siRNAs for SSX1 sequences target only SS18-SSX1. We synthesized two siRNAs targeting SS18-SSX1 to eliminate off-target effects. Immunoblotting showed that both 
A

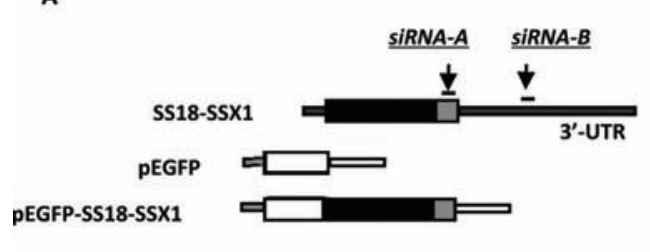

\section{.}

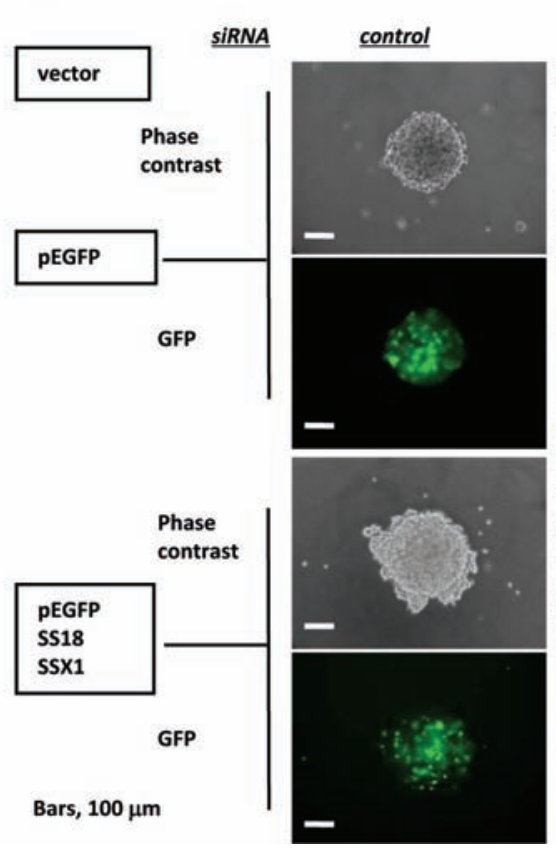

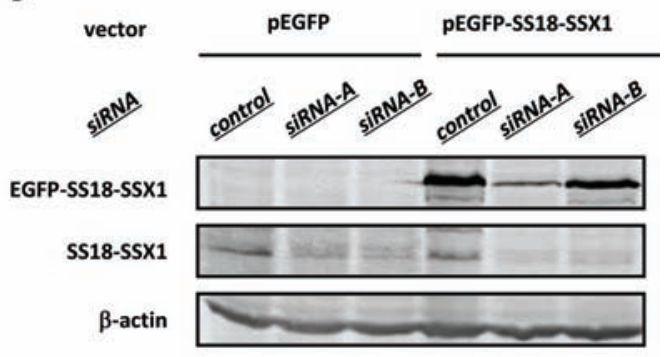

SIRNA-A
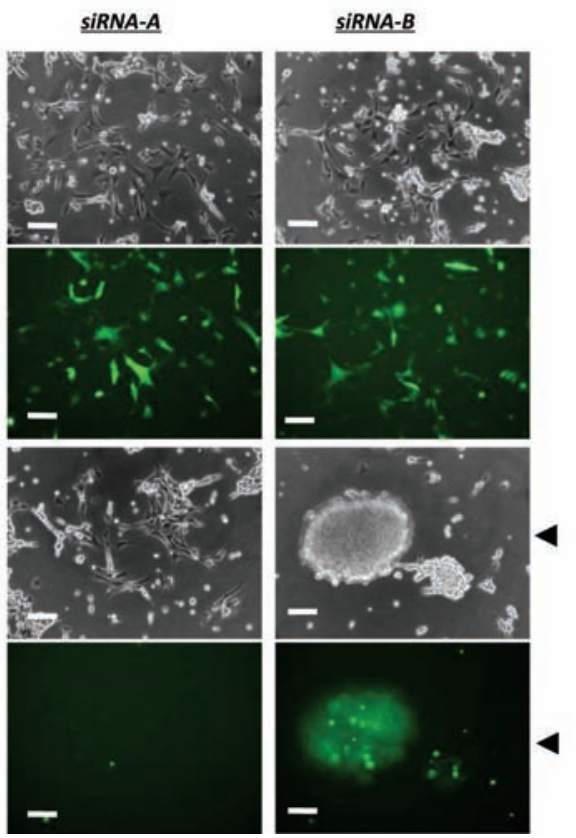

Figure 2. Rescue of morphological changes by expression of EGFP-SS18-SSX1 in YamatoSS. (A) Schematic diagram of SS18-SSX1 fusion gene, pEGFP and pEGFP-SS18-SSX1. The targets of siRNA-A and siRNA-B are indicated by arrows. (B) Immunoblot analysis of YamatoSS co-transfected with the siRNA and the expression vector depicted in (A). The siRNA-A silenced both endogenous SS18-SSX1 fusion protein and EGFP-SS18-SSX1 because the targeted coding region is shared. In contrast, siRNA-B silenced only endogenous SS18-SSX1 fusion protein but not EGFP-SS18-SSX1, because it targets 3'-UTR of the fusion gene. (C) Re-expression of EGFP-SS18-SSX1 rescued the morphological changes of YamatoSS induced by silencing of SS18-SSX1 with siRNA-B (arrowheads).

siRNA-A and siRNA-B effectively downregulated the expression level of SS18-SSX1 compared with siRNA control (Fig. 1B), and the silencing effects continued for 7 days (data not shown).

Effects of SS18-SSX1 silencing on cell growth varied between the three SS cell lines: it inhibited growth of YaFuSS and YamatoSS cells, but enhanced it for AskaSS (Fig. 1C). However, we found that SS18-SSX1 silencing induced quite similar morphological changes in all three SS cell lines. The SS18-SSX1-silenced SS cells were spread out and scattered by enhanced adhesion to the extracellular matrix (ECM). YamatoSS showed a particularly dramatic shape change from spherical to attached after silencing of SS18-SSX1 (Fig. 1D).

Re-expression of EGFP-SS18-SSX1 rescued the morphological changes induced by silencing SS18-SSX1. To determine whether the morphological change was due to silencing of SS18-SSX1 or to off-target or other non-specific effects, we performed knockdown/rescue experiments. YamatoSS transfected with siRNA control, siRNA-A or siRNA-B was transfected with a pEGFP or pEGFP-SS18-SSX1 vector that contained a different 3'-UTR sequence from endogenous SS18-SSX1. As expected, immunoblotting revealed that siRNA-B silenced only endogenous SS18-SSX1 fusion protein but not EGFP-SS18-SSX1, because it targets 3'-UTR of endogenous SS18-SSX1, while siRNA-A silenced both the endogenous SS18-SSX1 fusion protein and EGFP-SS18SSX1 because it targets the shared coding region (Fig. 2A and B). We found that re-expression of EGFP-SS18-SSX1 rescued the morphological changes induced by siRNA-B, but that pEGFP-SS18-SSX1 could not rescue the morphological changes induced by siRNA-A, because siRNA-A silenced SS18-SSX1 and EGFP-SS18-SSX1 (Fig. 2C, arrowheads). Thus, we verified that the morphological change was a result of silencing of SS18-SSX1.

Transcriptional signature of SS18-SSX1 silencing. Next, to confirm the significance of this morphological regulation to SS18-SSX1 function, we analyzed the expression profile of three SS cell lines transfected with the siRNA control and siRNA-A (YamatoSS and YaFuSS) or siRNA-B (AskaSS) using Agilent Whole Human genome microarray; 1222 genes 
A

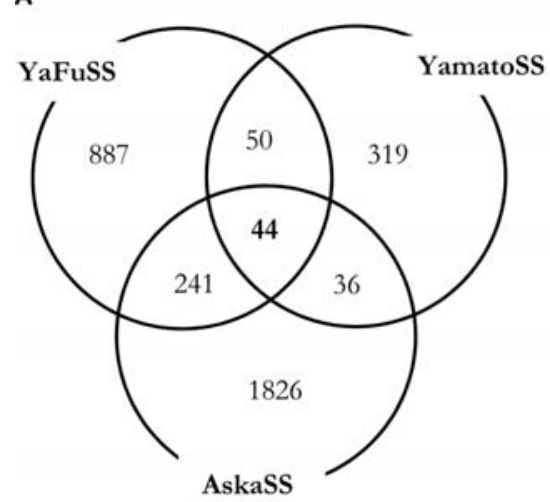

B

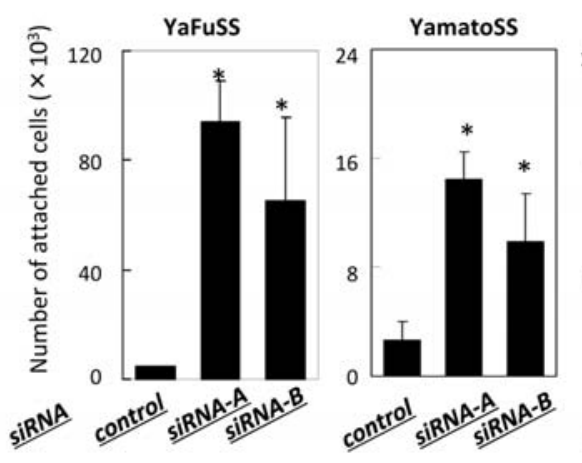

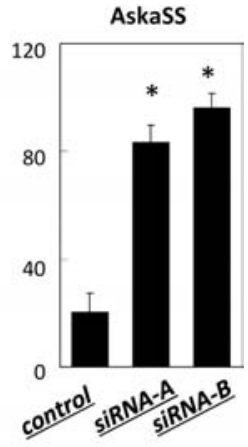

c

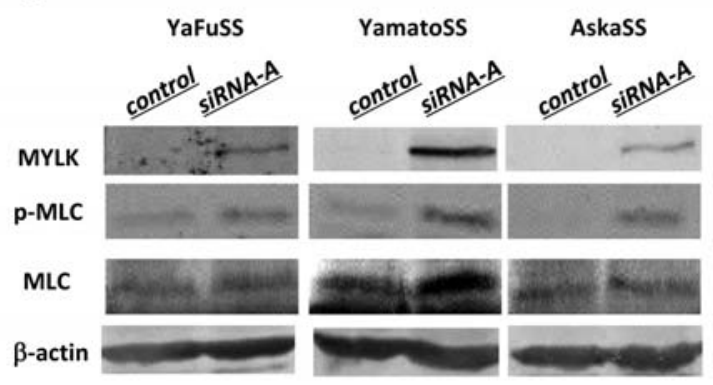

D

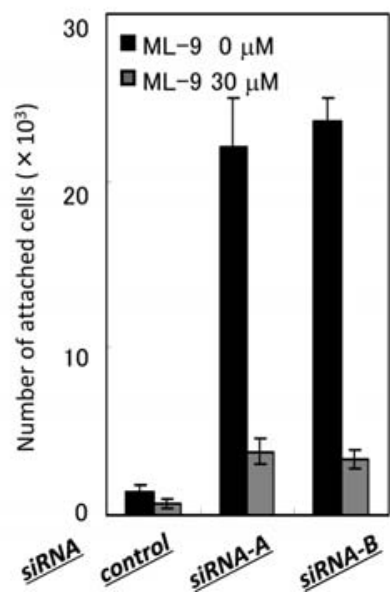

Figure 3. Involvement of SS18-SSX1 in cell adhesion. (A) Venn diagram of genes induced more than 2-fold by SS18-SSX1 silencing in three SS cell lines, as revealed by microarray analysis. (B) The silencing of SS18-SSX1 in three SS cell lines enhanced the adhesion to the culture dishes. Data are shown as mean \pm SD. ${ }^{*} \mathrm{P}<0.05$ compared with control. (C) The expression level of MYLK and the phosphorylation status of MLC were enhanced by SS18-SSX1 silencing in three SS cell lines, shown by immunoblotting analysis. (D) MYLK inhibitor prevented the cell adhesion induced by silencing of SS18-SSX1.

in YaFuSS, 449 genes in YamatoSS, and 2147 genes in AskaSS were induced more than 2-fold by silencing SS18SSX1. A Venn diagram showed that 44 genes were commonly upregulated in all three SS cell lines by silencing SS18-SSX1 (Fig. 3A). When these 44 genes were functionally classified according to the KEGG, they were mostly found to be involved in the focal adhesion pathway (Table I A). Therefore, morphological regulation by focal adhesion dynamics is one of the major biological targets of SS18-SSX1.

Silencing of SS18-SSX1 enhanced adhesion through induction of MYLK. In order to objectively quantify these morphological changes, we performed a cell adhesion assay. We found that silencing SS18-SSX1 increased the number of cells that adhered to the culture dish, as expected (Fig. 3B). Thus, we speculated that SS18-SSX1 inhibits the expression of adhesion molecules. To gain insight into the molecules downstream of SS18-SSX1, we interrogated microarray expression data from the tumor formed on SS18-SSX induction in a conditional mouse model (24). Of 6 focal adhesion genes upregulated by silencing SS18-SSX1 in this study (Table I B), myosin lightchain kinase $(M Y L K)$ was downregulated in the tumor formed on SS18-SSX induction. We confirmed that the protein level of $M Y L K$ and the phosphorylation status of $M L C$ were upregulated by silencing of SS18-SSX1 in all three SS cell lines (Fig. 3C). Addition of $30 \mu \mathrm{M}$ of ML-9, a specific inhibitor of MYLK, prevented cell adhesion (Fig. 3D).

The reciprocal effect of wild-type SS18 to SS18-SSX1 fusion gene. We investigated whether wild-type SS18 affects morphology and adhesion, because it was reported previously that wild-type SS18 promotes cell adhesion to an ECM (25). YamatoSS cells were cotransfected with expression vector encoding EGFP, EGFP-SS18 wild-type, or EGFP-SS18-SSX1 and siRNA-B or control siRNA (Fig. 4A). As mentioned above, EGFP-SS18-SSX1 rescued the morphological changes and the adhesion to ECM induced by siRNA-B; EGFP-SS18 wild-type did not rescue them. Moreover, EGFP-SS18 wildtype even enhanced adhesion to the ECM (Fig. 4B and C). These data indicate that SS18-SSX1 fusion protein exerts an inhibiting effect to wild-type SS18 on cell adhesion.

SS18-SSX1 facilitated anchorage-independent growth in vitro. Next, we investigated how SS18-SSX1 contributes to oncogenesis in SS. Silencing of SS18-SSX1 decreased the number of spheres under non-serum conditions (Fig. 5A). These 


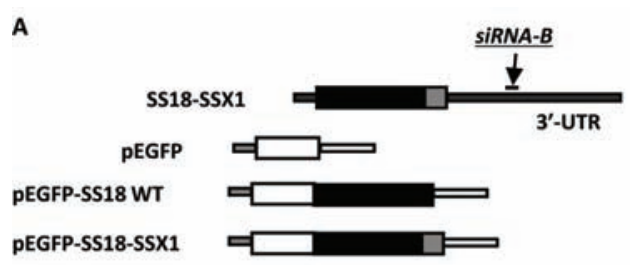

B
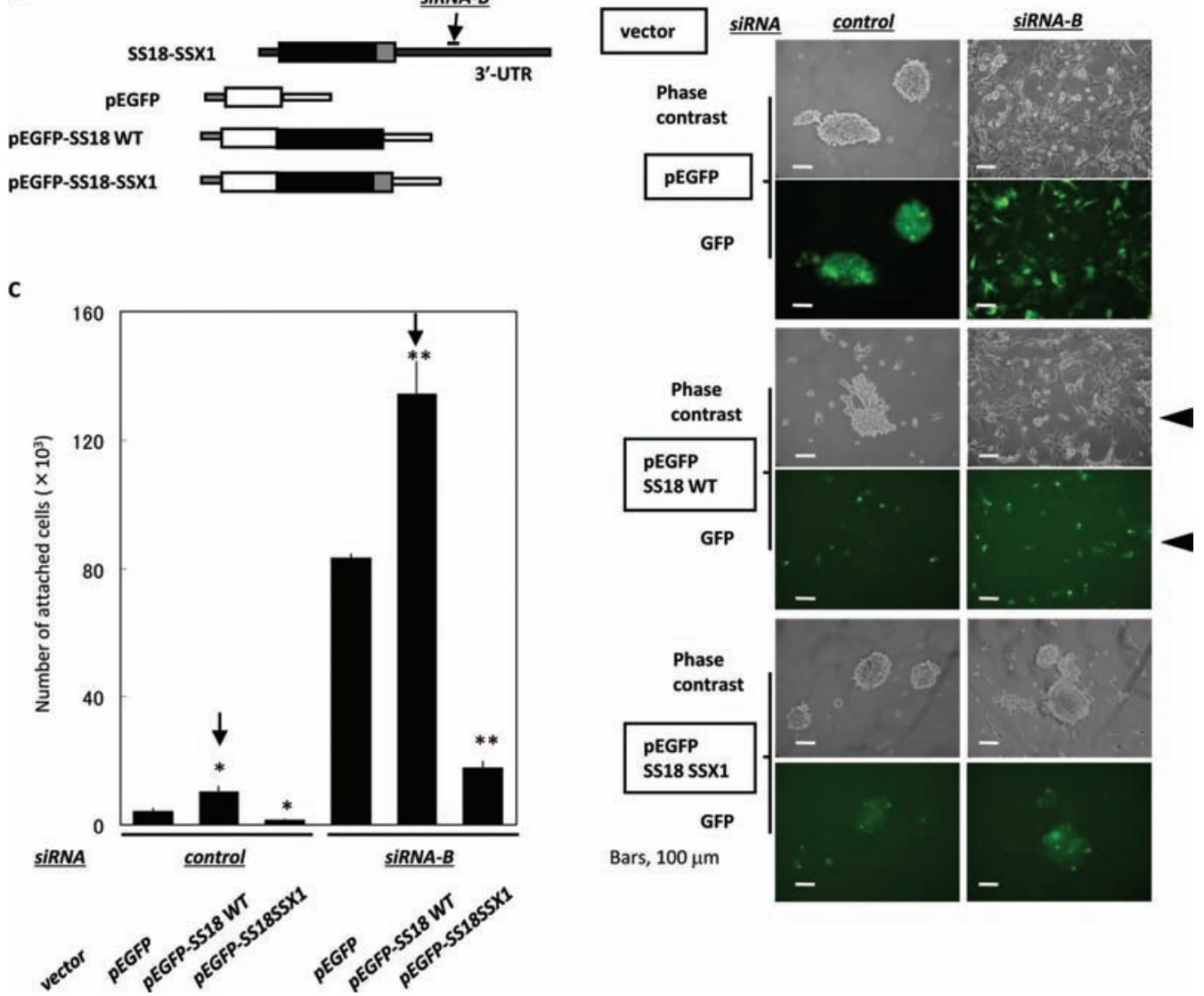

Figure 4. The reciprocal effect of wild-type SS18 on SS18-SSX1 fusion protein. (A) Schematic diagram of SS18-SSX1 fusion gene, pEGFP, pEGFP-SS18 wild-type, and pEGFP-SS18-SSX1. The target of siRNA-B is indicated by the arrow. (B) pEGFP-SS18 wild-type did not rescue the morphological changes caused by siRNA-B (arrowheads). (C) pEGFP-SS18 wild-type enhanced adhesion to the culture dishes, as monitored by cell adhesion assay (arrows). Data are shown as mean $\pm \mathrm{SD} .{ }^{*} \mathrm{P}<0.05$ compared with siRNA control and $\mathrm{pEGFP},{ }^{* *} \mathrm{P}<0.05$ compared with siRNA-B and $\mathrm{pEGFP}$.

Table I. SS18-SSX1 is mostly involved in the focal adhesion pathway.

A.

Pathways

No. of genes

P-value

Focal adhesion

Regulation of actin cytoskeleton

$1.95 \mathrm{E}-15$

ECM-receptor interaction

$3.96 \mathrm{E}-07$

Cell communication

0.000269

Calcium signaling pathway

0.000381

0.000752

B.

Gene symbol

Description

Fold change (silencing/control)

YaFuSS YamatoSS

AskaSS

\begin{tabular}{|c|c|c|c|c|}
\hline$C A V 1$ & Caveolin 1 & 9.00 & 3.88 & 11.7 \\
\hline MYLK & Myosin light chain kinase & 7.95 & 4.13 & 12.2 \\
\hline$C A V 3$ & Caveolin 3 & 7.87 & 3.74 & 23.1 \\
\hline LAMA4 & Laminin, $\alpha 4$ & 4.42 & 2.01 & 2.87 \\
\hline COL1A2 & Collagen, type I, $\alpha 2$ & 2.05 & 12.6 & 2.66 \\
\hline ACTN4 & Actinin, $\alpha 4$ & 2.62 & 2.18 & 2.12 \\
\hline
\end{tabular}

(A) KEGG pathway analysis of the 44 genes that showed more than 2-fold induction in all three SS cell lines on silencing of SS18-SSX1 (see Fig. 3A). Many were involved in the focal adhesion pathway (see Fig. 3B). (B) Six genes in the focal adhesion pathway in (A). 
A

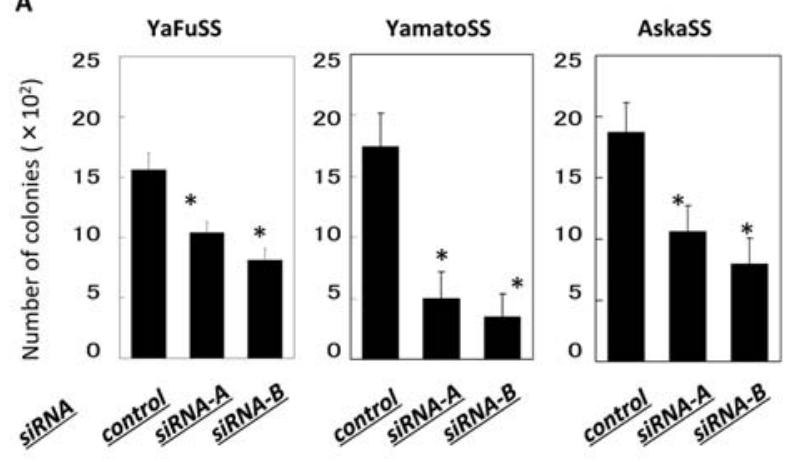

B

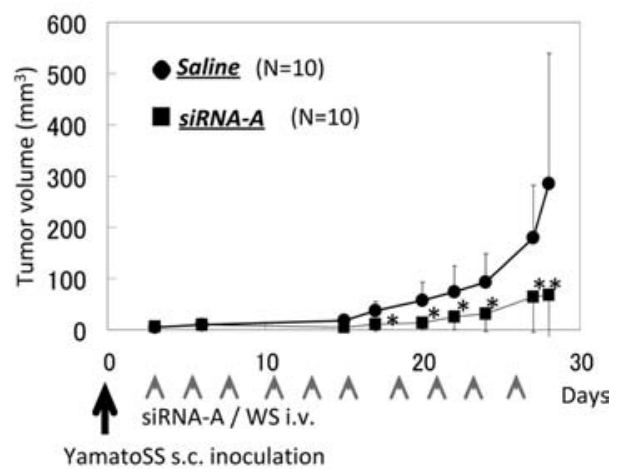

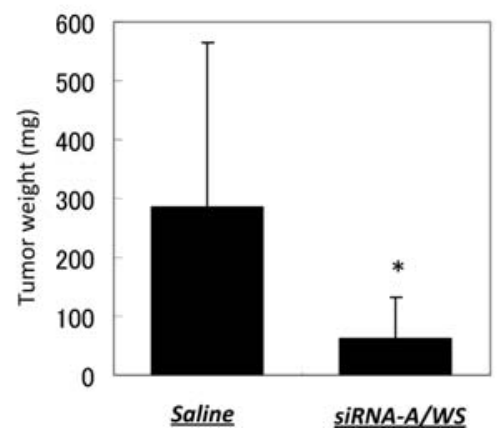

data suggest that SS18-SSX1 plays a role in oncogenesis by enhancing anchorage-independent growth.

In vivo application of SS18-SSX1 silencing. To test whether SS18-SSX1 silencing might inhibit tumor growth in a nude mouse xenograft model, we used 'wrapsome' (WS), which is a systemically injectable siRNA vehicle (26). The siRNAA/WS or saline alone was injected three times a week into the tail veins of nude mice, starting 3 days after the inoculation of YamatoSS into their flanks. siRNA-A/WS significantly reduced tumor growth in vivo (Fig. 5B and C).

\section{Discussion}

Identification of the SS18-SSX fusion gene in SS suggested the possibility of a new molecular target for the treatment of $\mathrm{SS}$, which will be more specific and less toxic than current treatments. Unfortunately, this hope has not yet been realized. We have investigated the function of SS18-SSX by silencing it using siRNA in three human SS cells lines, and verified whether this silencing has clinical relevance.

Previously, several downstream targets of SS18-SSX have been reported, including cyclinD1 (28), p21 (29), IGF2 (30), E-cadherin (31), TLE1 (32), EGR1 (33), EphB2 (34), and COM1 (35). Present microarray analysis did not show any of these to be changed by more than 1.5-fold in all three of our SS cell lines. While most of these genes were identified after exogenous SS18-SSX expression induction in various kinds of cells, the function of SS18-SSX fusion protein is different according to cellular background $(21,23)$. Thus the gain of function study in inappropriate cell may not reflect the function of SS18-SSX protein in SS. Our microarray
Figure 5. Effects of SS18-SSX1 silencing on anchorage-independent growth in vitro and tumor growth in vivo. (A) Silencing of SS18-SSX1 decreased the number of spheres in non-serum 3D culture conditions in the presence of EGF, bFGF, NSF-1, and $0.8 \%$ methylcellulose ( $n=3$ in each group). Data are shown as mean $\pm \mathrm{SD}$. ${ }^{*} \mathrm{P}<0.05$ compared with control. (B) Time-dependent changes in tumor volume. YamatoSS cells $\left(1 \times 10^{7}\right)$ were subcutaneously transplanted into the flank of nude mice on day 0 . WS containing siRNA-A or saline alone was intravenously injected three times a week, as indicated by arrowheads, from day 3 to 24 . Nude mice were sacrificed and examined on day 28 ( $n=10$ in each group). (C) The mean tumor weight was significantly decreased by treatment with siRNA-A/WS. Data are shown as mean $\pm \mathrm{SD}$. ${ }^{*} \mathrm{P}<0.05$

analysis showed that silencing of SS18-SSX1 mainly affected the focal adhesion pathway. In accord with the array data, silencing of SS18-SSX1 enhances adhesion to the culture dish, while re-expression of SS18-SSX1 rescued this phenotype. It has previously been reported that wild-type $S S 18$ promotes cell adhesion and is involved in cytoskeletal organization $(25,36,37)$. We confirmed these results finding that wild-type SS18 expression into SS enhanced adhesion to the culture dishes. We also found that SS18-SSX1 antagonized wild-type SS18 in cell adhesion.

Of the 6 focal adhesion pathway genes commonly upregulated by silencing SS18-SSX1 in this study, MYLK was found to be downregulated in the tumor formed on SS18-SSX induction in a conditional mouse model (24). We confirmed that the protein level of MYLK and the phosphorylation status of $M L C$ were upregulated by silencing of SS18-SSX1 in all three SS cell lines. Moreover, MYLK inhibitor blocked morphological changes and cell adhesion by silencing of SS18-SSX1. Thus, we speculate that SS18-SSX1 inhibits cell adhesion at least in part via MYLK suppression. Of note, SS18-SSX1 silencing did not inhibit but enhanced cell growth in AskaSS in normal 2D culture plates, while in 3D culture the silencing of SS18-SSX1 decreased the number of spheres under non-serum conditions. This suggests that SS18-SSX1 is not crucial for anchorage-dependent growth but is required for anchorage-independent growth. The ability of tumor cells to proliferate in the absence of adhesion to ECM correlates closely with tumorigenicity in animal models (38). This property of cancer cells presumably reflects the ability of tumor cells to survive and grow in inappropriate locations in vivo, as occurs in invasion and metastasis. MYLK is a target for p21-activated kinases (PAKs), which decrease MYLK 
activity by phosphorylation of MYLK (39). Current evidence suggests that PAKs play an important role in anchorageindependent growth. For example, the kinase-inactive alleles of PAK1 block Ras transformation of Rat-1 fibroblasts (40), and the expression of active $P A K 4$ mutant has transforming potential in NIH3T3 (41). In this study, the expression of MYLK was downregulated in all three SS cell lines and upregulated by the silencing of SS18-SSX1 without alteration of $P A K$ expression. Future investigation will be required to elucidate the mechanism, how MYLK controls the transforming activity in SS.

The silencing of gene expression by siRNA is a powerful tool for genetic analysis. However, delivery of siRNA into targets in vivo is a major obstacle for RNAi-based therapy. To overcome this problem, a drug delivery system needs to (a) protect the siRNA from degradation, (b) suppress nonspecific uptake by non-target tissues, and (c) mediate accumulation of siRNA within the target tissues and cells. WS was specifically developed to enable systemic delivery of siRNA (27). WS contains siRNA and a cationic lipofection complex in a core that is fully enveloped by a neutral lipid bilayer of hydrophilic polymers. The outer lipid bilayer is composed of neutral phospholipids and is PEGylated to protect siRNA from degradation and to inhibit non-specific interactions with the negatively charged endothelial cell membrane and plasma proteins. WS has a diameter of $100 \mathrm{~nm}$, which facilitates accumulation within tumors via the enhanced permeability and retention effect and suppresses renal excretion and reticuloendothelial uptake (26). Tumor growth in mice treated with siRNA-A/WS showed an initial delay. We consider that treatment with siRNA-A/WS assists in the prevention of initial establishment of tumors from the injected tumor cells in these mice and slows the growth of tumors by downregulating the expression of the oncogenic fusion protein SS18-SSX1.

In conclusion, SS18-SSX1 inhibits adhesion to ECM and enhances anchorage-independent growth; therefore, siRNA has potential molecular target therapy for the treatment of human SS.

\section{Acknowledgements}

We are grateful to Dr Junya Toguchida for providing the human synovial sarcoma cell line YaFuSS. We are grateful to Dr Nobuhiro Yagi (Kyowa Hakko Kirin Co., Ltd.) for providing the WS containing siRNA-A.

\section{References}

1. Smith S, Reeves BR, Wong L and Fisher C: A consistent chromosome translocation in synovial sarcoma. Cancer Genet Cytogenet 26: 179-180, 1987.

2. Clark J, Rocques PJ, Crew AJ, Gill S, Shipley J, Chan AM, Gusterson BA and Cooper CS: Identification of novel genes, SYT and SSX, involved in the $\mathrm{t}(\mathrm{X} ; 18)(\mathrm{p} 11.2 ; \mathrm{q} 11.2)$ translocation found in human synovial sarcoma. Nat Genet 7: 502-508, 1994.

3. Crew AJ, Clark J, Fisher C, Gill S, Grimer R, Chand A, Shipley J, Gusterson BA and Cooper CS: Fusion of SYT to two genes, SSX1 and SSX2, encoding proteins with homology to the Kruppel-associated box in human synovial sarcoma. EMBO J 14: 2333-2340, 1995.

4. Skytting B, Nilsson G, Brodin B, Xie Y, Lundeberg J, Uhlen M and Larsson O: A novel fusion gene, SYT-SSX4, in synovial sarcoma. J Natl Cancer Inst 91: 974-975, 1999.
5. Takenaka S, Ueda T, Naka N, Araki N, Hashimoto N, Myoui A, Ozaki T, Nakayama T, Toguchida J, Tanaka K, Iwamoto Y, Matsumine A, Uchida A, Ieguchi M, Kaya M, Wada T, Baba I, Kudawara I, Aoki Y and Yoshikawa H: Prognostic implication of SYT-SSX fusion type in synovial sarcoma: a multi-institutional retrospective analysis in Japan. Oncol Rep 19: 467-476, 2008.

6. Wohlbold L, van der Kuip H, Miething C, Vornlocher HP, Knabbe C, Duyster J and Aulitzky WE: Inhibition of bcr-abl gene expression by small interfering RNA sensitizes for imatinib mesylate (STI571). Blood 102: 2236-2239, 2003.

7. Koldehoff M, Steckel NK, Beelen DW and Elmaagacli AH: Therapeutic application of small interfering RNA directed against bcr-abl transcripts to a patient with imatinib-resistant chronic myeloid leukaemia. Clin Exp Med 7: 47-55, 2007.

8. Weis K, Rambaud S, Lavau C, Jansen J, Carvalho T, CarmoFonseca M, Lamond A and Dejean A: Retinoic acid regulates aberrant nuclear localization of PML-RAR alpha in acute promyelocytic leukemia cells. Cell 76: 345-356, 1994.

9. De Bruijn DR, Baats E, Zechner U, de Leeuw B, Balemans M, Olde Weghuis D, Hirning-Folz U and Geurts van Kessel AG: Isolation and characterization of the mouse homolog of SYT, a gene implicated in the development of human synovial sarcomas. Oncogene 13: 643-648, 1996.

10. De Bruijn DR, Peters WJ, Chuva de Sousa Lopes SM, van Dijk AH, Willemse MP, Pfundt R, de Boer P and Geurts van Kessel A: Targeted disruption of the synovial sarcoma-associated SS18 gene causes early embryonic lethality and affects PPARBP expression. Hum Mol Genet 15: 2936-2944, 2006.

11. Perani M, Ingram CJ, Cooper CS, Garrett MD and Goodwin GH: Conserved SNH domain of the proto-oncoprotein SYT interacts with components of the human chromatin remodelling complexes, while the QPGY repeat domain forms homo-oligomers. Oncogene 22: 8156-8167, 2003.

12. Thaete C, Brett D, Monaghan P, Whitehouse S, Rennie G, Rayner E, Cooper CS and Goodwin G: Functional domains of the SYT and SYT-SSX synovial sarcoma translocation proteins and co-localization with the SNF protein BRM in the nucleus. Hum Mol Genet 8: 585-591, 1999.

13. Soulez M, Saurin AJ, Freemont PS and Knight JC: SSX and the synovial-sarcoma-specific chimaeric protein SYT-SSX colocalize with the human Polycomb group complex. Oncogene 18: 2739-2746, 1999

14. Margolin JF, Friedman JR, Meyer WK, Vissing H, Thiesen HJ and Rauscher FJ III: Kruppel-associated boxes are potent transcriptional repression domains. Proc Natl Acad Sci USA 91: 4509-4513, 1994.

15. Moosmann P, Georgiev O, Le Douarin B, Bourquin JP and Schaffner W: Transcriptional repression by RING finger protein TIF1 beta that interacts with the KRAB repressor domain of KOX1. Nucleic Acids Res 24: 4859-4867, 1996.

16. Gure AO, Tureci O, Sahin U, Tsang S, Scanlan MJ, Jager E, Knuth A, Pfreundschuh M, Old LJ and Chen YT: SSX: a multigene family with several members transcribed in normal testis and human cancer. Int J Cancer 72: 965-971, 1997.

17. Naka N, Joyama S, Tsukamoto Y, Yoshioka K, Hashimoto N, Ujiiye T, Hayashi T, Kawase M, Mano M, Ishiguro S, Myoui A, Ueda T, Yoshikawa H, Araki N and Itoh K: Quantification of SSX mRNA expression in human bone and soft tissue tumors using nucleic acid sequence-based amplification. J Mol Diagn 7: 187-197, 2005.

18. Valmori D, Qian F, Ayyoub M, Renner C, Merlo A, Gnjatic S, Stockert E, Driscoll D, Lele S, Old LJ and Odunsi K: Expression of synovial sarcoma X (SSX) antigens in epithelial ovarian cancer and identification of SSX-4 epitopes recognized by $\mathrm{CD}^{+} \mathrm{T}$ cells. Clin Cancer Res 12: 398-404, 2006.

19. Ayyoub M, Merlo A, Hesdorffer CS, Rimoldi D, Speiser D, Cerottini JC, Chen YT, Old LJ, Stevanovic S and Valmori D: $\mathrm{CD}^{+} \mathrm{T}$ cell responses to SSX-4 in melanoma patients. J Immunol 174: 5092-5099, 2005.

20. Ayyoub M, Brehm M, Metthez G, Talbot S, Dutoit V, Taub RN, Keohan ML, Gure AO, Chen YT, Williamson B, Jungbluth AA, Old LJ, Hesdorffer CS and Valmori D: SSX antigens as tumor vaccine targets in human sarcoma. Cancer Immun 3: 13, 2003.

21. Nagai M, Tanaka S, Tsuda M, Endo S, Kato H, Sonobe H, Minami A, Hiraga $\mathrm{H}$, Nishihara $\mathrm{H}$, Sawa $\mathrm{H}$ and Nagashima $\mathrm{K}$ : Analysis of transforming activity of human synovial sarcomaassociated chimeric protein SYT-SSX1 bound to chromatin remodeling factor hBRM/hSNF2 alpha. Proc Natl Acad Sci USA 98: 3843-3848, 2001. 
22. Dos Santos NR, de Bruijn DR, Kater-Baats E, Otte AP and van Kessel AG: Delineation of the protein domains responsible for SYT, SSX, and SYT-SSX nuclear localization. Exp Cell Res 256: 192-202, 2000.

23. Haldar M, Hedberg ML, Hockin MF and Capecchi MR: A CreER-based random induction strategy for modeling translocation-associated sarcomas in mice. Cancer Res 69: 3657-3664, 2009.

24. Haldar M, Hancock JD, Coffin CM, Lessnick SL and Capecchi MR: A conditional mouse model of synovial sarcoma: insights into a myogenic origin. Cancer Cell 11: 375-388, 2007.

25. Eid JE, Kung AL, Scully R and Livingston DM: p300 interacts with the nuclear proto-oncoprotein SYT as part of the active control of cell adhesion. Cell 102: 839-848, 2000.

26. Yagi N, Manabe I, Tottori T, Ishihara A, Ogata F, Kim JH, Nishimura S, Fujiu K, Oishi Y, Itaka K, Kato Y, Yamauchi M and Nagai R: A nanoparticle system specifically designed to deliver short interfering RNA inhibits tumor growth in vivo. Cancer Res 69: 6531-6538, 2009.

27. Yamauchi M, Kusano H, Saito E, Iwata T, Nakakura M, Kato Y, Uochi T, Akinaga S and Aoki N: Improved formulations of antisense oligodeoxynucleotides using wrapped liposomes. J Control Release 114: 268-275, 2006.

28. Xie Y, Skytting B, Nilsson G, Gasbarri A, Haslam K, Bartolazzi A, Brodin B, Mandahl N and Larsson O: SYT-SSX is critical for cyclin D1 expression in synovial sarcoma cells: a gain of function of the $\mathrm{t}(\mathrm{X} ; 18)(\mathrm{p} 11.2 ; \mathrm{q} 11.2)$ translocation. Cancer Res 62: 3861-3867, 2002.

29. Tsuda M, Watanabe T, Seki T, Kimura T, Sawa H, Minami A, Akagi T, Isobe K, Nagashima $\mathrm{K}$ and Tanaka S: Induction of p21(WAF1/CIP1) by human synovial sarcoma-associated chimeric oncoprotein SYT-SSX1. Oncogene 24: 7984-7990, 2005.

30. Fernebro J, Francis P, Eden P, Borg A, Panagopoulos I, Mertens F, Vallon-Christersson J, Akerman M, Rydholm A, Bauer HC, Mandahl N and Nilbert M: Gene expression profiles relate to SS18/SSX fusion type in synovial sarcoma. Int J Cancer 118: 1165-1172, 2006.

31. Saito T, Nagai M and Ladanyi M: SYT-SSX1 and SYT-SSX2 interfere with repression of E-cadherin by snail and slug: a potential mechanism for aberrant mesenchymal to epithelial transition in human synovial sarcoma. Cancer Res 66: 6919-6927, 2006.
32. Terry J, Saito T, Subramanian S, Ruttan C, Antonescu CR, Goldblum JR, Downs-Kelly E, Corless CL, Rubin BP, van de Rijn M, Ladanyi $M$ and Nielsen TO: TLE1 as a diagnostic immunohistochemical marker for synovial sarcoma emerging from gene expression profiling studies. Am J Surg Pathol 31: 240-246, 2007.

33. Lubieniecka JM, de Bruijn DR, Su L, van Dijk AH, Subramanian S, van de Rijn M, Poulin N, van Kessel AG and Nielsen TO: Histone deacetylase inhibitors reverse SS18-SSX-mediated polycomb silencing of the tumor suppressor early growth response 1 in synovial sarcoma. Cancer Res 68: 4303-4310, 2008.

34. Barco R, Hunt LB, Frump AL, Garcia CB, Benesh A, Caldwell RL and Eid JE: The synovial sarcoma SYT-SSX2 oncogene remodels the cytoskeleton through activation of the ephrin pathway. Mol Biol Cell 18: 4003-4012, 2007.

35. Ishida M, Miyamoto $M$, Naitoh $S$, Tatsuda $D$, Hasegawa $T$, Nemoto T, Yokozeki H, Nishioka K, Matsukage A, Ohki M and Ohta T: The SYT-SSX fusion protein down-regulates the cell proliferation regulator COM1 in $\mathrm{t}(\mathrm{X} ; 18)$ synovial sarcoma. Mol Cell Biol 27: 1348-1355, 2007.

36. Chittezhath M, Frump AL, Jourquin J, Lobdell N and Eid JE: The proto-oncoprotein SYT (SS18) controls ATP release and regulates cyst formation by polarized MDCK cells. Exp Cell Res 314: 3551-3562, 2008.

37. Kim J, Swee M and Parks WC: Cytosolic SYT/SS18 isoforms are actin-associated proteins that function in matrix-specific adhesion. PLoS One 4: E6455, 2009.

38. Freedman VH and Shin SI: Cellular tumorigenicity in nude mice: correlation with cell growth in semi-solid medium. Cell 3: 355-359, 1974

39. Sanders LC, Matsumura F, Bokoch GM and de Lanerolle P: Inhibition of myosin light chain kinase by p21-activated kinase. Science 283: 2083-2085, 1999.

40. Tang Y, Chen Z, Ambrose D, Liu J, Gibbs JB, Chernoff J and Field J: Kinase-deficient Pak1 mutants inhibit Ras transformation of Rat-1 fibroblasts. Mol Cell Biol 17: 4454-4464, 1997.

41. Callow MG, Clairvoyant F, Zhu S, Schryver B, Whyte DB, Bischoff JR, Jallal B and Smeal T: Requirement for PAK4 in the anchorage-independent growth of human cancer cell lines. J Biol Chem 277: 550-558, 2002. 